Part of Journal of Research of the National Bureau of Standards, Volume 33, August 1944

\title{
A PHYSICAL METHOD FOR DETERMINING RESIDUAL WATER AND OTHER VOLATILE MATERIALS IN PURE SUBSTANCES
}

\author{
By Frank W. Schwab and Edward Wichers
}

\begin{abstract}
A method is described for determining small amounts of water and other volatile substances present as impurities in various organic and inorganic compounds. The impurity is separated by fusing the substance in a cell attached to a collecting system and allowing it to freeze slowly while the vapors are collected by pumping them into a trap of known volume, cooled by liquid air. When the trap is warmed to room temperature, the pressure of the vapor within it, if below saturation, together with the temperature and volume, determine the quantity of impurity in terms of moles and if its identity is known, in terms of weight. An auxiliary procedure permits the impurity to be isolated as a liquid, in a capillary container, and thus to be identified.

It was found that the current Standard Samples of benzoic acid (39f and 140) contain less than 0.002 percent of water and do not adsorb water on exposure to an atmosphere of high humidity. The method is further illustrated by the determination of residual solvents in acetanilide crystallized from benzene and from a mixture of alcohol and water, and of water present in potassium dichromate as entrapped mother liquor.
\end{abstract}

\section{CONTENTS}

I. Introduction Page

II. Apparatus and procedure

III. Experimental Results _._.

1. Determination of water in benzoic acid

2. Determination of benzene in acetanilide _............... 126

3. Determination of a mixture of water and alcohol in acetanilide. 126

4. Determination of water in potassium dichromate $\ldots . . . . . .126$

IV. Discussion

\section{INTRODUCTION}

In connection with a study of the properties of benzoic acid relative to the use of its freezing point as a thermometric fixed point, it became necessary to determine the amount of water retained by the substance under various conditions. The method devised for the purpose is believed to have advantages of simplicity and sensitivity, and possibly of accuracy, over previously published procedures which might have been used. No attempt will be made here to review the extensive literature dealing with the determination of water in organic substances. Experience in determining the purity of benzoic acid 
from its freezing range ${ }^{1}$ had shown that water does not appear to form solid solutions with benzoic acid, although it is moderately soluble in the fused acid. It therefore appeared that any water retained by the crystalline acid must be held either by adsorption on the crystal surfaces or by inclusion within crystals produced from and aqueous solution or from fused benzoic acid containing dissolved water. It seemed possible, therefore, to separate water by melting and freezing the acid in an evacuated system, and collecting the vaporized water in a suitable manner. Because of the small amounts of water involved and because water was the only volatile impurity known to be present, the method of collection used was to pump the water vapor into a trap cooled with liquid air. Then the amount collected was determined by warming the trap to room temperature and observing the pressure of the vapor. From the known volume of the trap, together with the temperature and the pressure (if below the saturation pressure), the quantity of water could be directly calculated. If the pressure was at saturation or near it, the determination was repeated with a larger trap or a smaller weight of sample.

An auxiliary procedure was to condense the vapor from the trap, where it was first collected, in a small capillary tube in which its volume could be measured with the aid of a microscope. It was possible to measure some of the properties of the liquid, such as its freezing point and refractive index, and thus to identify impurities of uncertain composition or to estimate the composition of a mixture of two known volatile impurities. With these variations, the method becomes generally applicable to the determination of small amounts of volatile impurities in fusible substances which are stable at their melting points. If the substance itself has a significant vapor pressure, the problem is not so simple and involves special considerations similar to those described by Shepherd ${ }^{2}$ in determining the purity of condensed gases.

\section{APPARATUS AND PROCEDURE}

The apparatus is shown in figure 1. A and B are two cells of nearly equal capacity (about $50 \mathrm{ml}$ ) attached through lubricated ground joints to the rest of the train. One of the cells (A) is the container for the sample and the other (B) provides a control or blank of the amount of water and carbon dioxide contained in the air or adsorbed on the walls of the cell at the time of the experiment. (1) is a threeway stopcock through which either A or B can be connected to the train, and (2) is a stopcock not needed or used in the work described in this paper, but which provides connection to other apparatus not shown. C is a differential manometer (normally, but not necessarily, filled with mercury) connected to the system through the stopcocks 3 , 4 , and 5. Stopcock 6 connects the system to a source of dry air, free of carbon dioxide. D is a trap whose internal volume, together with that of the adjacent leg of the manometer, is known. It is provided with a stopcock, 7 , and is connected to the train by means of lubricated ground joints. Three traps, with capacities of 21,66 , and 121 $\mathrm{ml}$, respectively, were used alternatively in the experimental work to

${ }_{1 \mathrm{k}} \mathrm{F}$. W. Schwab and Edward Wichers, Precise measurement of the freezing range as a means of determining the purity of a substance, Temperature-Its Measurement and Control in Science and Industry, p. 256-264 (Reinhold Publishing Corporation, New York, N. Y., 1941); also see Frank W. Schwab and Edward Wichers, Preparation of benzoic acid of high purity, J. Research NBS 25, 747 (1940) RP1351.

2 Martin Shepherd, A critical test for the purity of gases, BS J. Research 12, 185 (1934) RP643. 
be described. Each contained a plug of glass cotton to prevent the escape of minute ice crystals formed when water vapor enters the chilled trap. E is a thin-walled capillary tube used, when desired, to collect the liquid impurity by distillation from trap D. F is another trap like D, but serves only as a guard tube to prevent access of moisture from the line leading to the vacuum pump. This line is also provided with a stopcock (8). The stopcocks were of $2-\mathrm{mm}$ bore; the inside diameter of the tubing connecting the parts of the train was 3 to $4 \mathrm{~mm}$.

To make a determination, assemble the apparatus as shown in figure 1 , with both cells, A and B, empty. Cool the trap D with liquid air and evacuate the entire system to a pressure not higher than a few hundredths of a millimeter of mercury. Fill the system with air free of carbon dioxide and dried by passing it over phosphorus pentoxide or through a suitable trap cooled with liquid air, and evacuate again. Repeat this cycle two or three times to aid in the removal

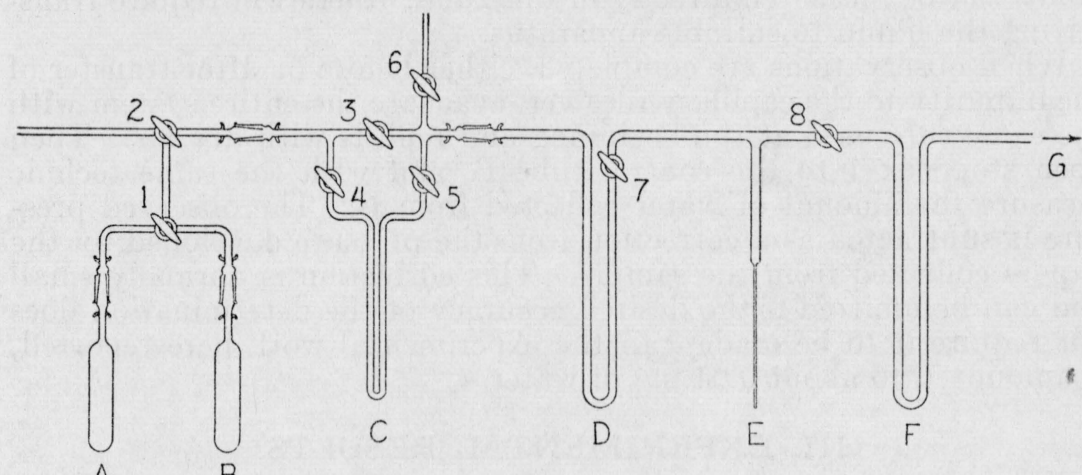

FIGURE 1.-Apparatus for determining residual water and other volatile materials in pure substances.

$A$, Cell for the sample; $B$, cell for control; $C$, manometer; $D$, trap of known volume; $E$, capillary container; $F$, trap; $G$, vacuum connection; $1,2,3$, etc., $2 \mathrm{~mm}$ stopcocks.

of water adsorbed on the surfaces of the apparatus. Finally, fill the system again with dry air, close stopcock 1 , and remove the two cells $A$ and B. Handle the two cells as nearly alike as possible. Transfer a suitable weight of sample (usually $10 \mathrm{~g}$ ) to $\mathrm{A}$ and reattach both cells to the train. Cool traps D and F with liquid air, open stopcock 1 to the cell containing the sample, lower the pressure in the system by several centimeters of mercury and maintain this reduced pressure during the next steps of the procedure by using the manometer to observe changes in pressure. Protect the lubricated joint of cell A with a suitable shield, warm the sample gently, and finally fuse it completely. ${ }^{3}$ Let the liquid freeze slowly, add some heat with a flame, if necessary, to prevent rapid freezing, and further reduce the pressure in the system to complete evacuation. Let the pump run for several minutes with stopcocks 3,4 , and 5 open and with 6 closed. Then close cocks 3,4 , and 7 . Let the trap $D$ and the manometer warm to the temperature of the room. Examine the walls of the trap closely

\footnotetext{
If the substance has a melting point too high to be fused in glass and the water or other volatile impurity is present as liquid trapped within the crystals, heating to a temperature high enough to insure thorough decrepitation of the solid can often be substituted for actual fusion.
} 


\section{Journal of Research of the National Bureau of Standards}

for droplets of liquid and note whether the manometer reading indicates a pressure close to the saturation pressure of the liquid that is being determined. If the pressure is at or near saturation, repeat the determination with a smaller sample or with a trap of larger capacity. If the pressure is obviously below saturation, observe the pressure accurately and note the temperature of the room. From the temperature, pressure, and volume, calculate the molal quantity of the vapor. If the identity of the impurity is known, the calculation is made, if desired, in terms of its mass.

If the impurity is to be identified, evacuate the portion of the system between stopcocks 7 and 8 , while cooling the guard trap F. Then close cock 8 and cool the capillary tube $\mathrm{E}$ with liquid air. Gently warm the parts of the train leading to $\mathrm{E}$ to promote the transfer of impurity into the capillary. When the transfer is complete, as evidenced by balance in the manometer, seal off the capillary tube. Some of the properties of the liquified impurity, e. g., its melting point, can be measured directly in this tube; others will require transferring the liquid to suitable apparatus.

When observations are completed, either before or after transfer of the impurity to the capillary receiver, evacuate the entire system with the same care used at the beginning and refill it with dry air. Then open stopcock 1 to the control tube $B$, and with the same technic measure the amount of water collected from B. The observed pressure is subtracted as a correction from the pressure developed by the vapors collected from the sample. This correction is normally small and can be omitted if the desired accuracy of the determination does not require it to be made. In the experimental work here reported, it amounted to about $0.04 \mathrm{mg}$ of water.

\section{EXPERIMENTAL RESULTS}

To find the magnitude of errors in the determination of water which might be caused by the retention of water on the relatively large area of glass surface of the apparatus, known small amounts of water were introduced and determined. The water was provided in the form of sodium dichromate dihydrate. Well-formed crystals of this salt were broken, and tiny fragments from the inside of the large crystals were weighed and quickly transferred to the sample container. During this operation larger fragments of the salt showed no evidence either of deliquescence or efflorescence. The tiny crystalline fragments lost most of their water when the cell was heated to $100^{\circ} \mathrm{C}$, but they were heated to fusion in accordance with the procedure given in the preceding section. From four samples of the salt weighing $3.66,2.77$, 1.70 , and $1.29 \mathrm{mg}$, corresponding to $0.44,0.33,0.21$, and $0.16 \mathrm{mg}$ of water, respectively, the amounts of water recovered were $0.37,0.26$, 0.23 , and $0.16 \mathrm{mg}$. In terms of $10 \mathrm{~g}$ samples used for the determination of water in benzoic acid, these results correspond to a maximum error of 0.0007 percent and an average error of 0.0004 percent. This apparent accuracy seemed sufficient for the purpose, but it might be improved by refinements of the apparatus and technic.

\section{DETERMINATION OF WATER IN BENZOIC ACID}

During the 30 years or more that benzoic acid has been used as a standard substance, there has always been some concern about its 
possible hygroscopicity. Morey ${ }^{4}$ suggested fusing the material so as to reduce, for a given weight of sample, the surface area on which adsorption could occur. Weaver ${ }^{5}$ measured what he thought to be adsorption. He found, by titration, a decrease of 0.08 percent in the acidimetric value of a sample of benzoic acid that had been kept in a glass-stoppered bottle for about a year, and later detected water in it directly, although by a qualitative test. Swiętosławski and coworkers ${ }^{67}$ reported that they were able to detect as little as 0.001 percent of water in $15 \mathrm{~g}$ of benzoic acid, by an ebulliometric method. They further reported the water content of benzoic acid, Standard Sample 48a, issued by the National Bureau of Standards, as 0.0047 \pm 0.0008 percent. They also claimed that a pellet of benzoic acid, which contained 0.002 percent of water, had a water content of 0.012 percent after exposure in "a saturated atmosphere" of water vapor at $25^{\circ} \mathrm{C}$ for 3 hours. Jessup ${ }^{8}$ was unable to detect the adsorption of water by the indirect method of determining the heat of combustion of benzoic acid before and after its exposure in an environment of high relative humidity.

The method herein described was used to determine the water content of two current Standard Samples of benzoic acid, ${ }^{9}$ and also to learn whether these samples gain water when exposed to air of high relative humidity. Ten-gram portions of the acid, contained in cells like $\mathrm{A}$ and $\mathrm{B}$ in figure 1 , were stored over a saturated solution of sodium carbonate decahydrate at about $23^{\circ} \mathrm{C}$ for 45 days. This saturated solution maintains a relative humidity of 90 percent at $23^{\circ} \mathrm{C}$. It seems reasonable to believe that equilibrium between the crystals of the acid and the water in the air would be closely approached, if not completely realized, in the period named. Empty cells, to serve as controls, were stored with those containing the acid and were attached to the water-determining train simultaneously with them.

With the procedure described, the water contents of two $10-\mathrm{g}$ samples of Standard Sample 39f not exposed to the humid atmosphere were 0.0015 and 0.0015 percent. $^{10}$ For two samples of the same acid, after exposure, the values were 0.0019 and 0.0019 percent. Single samples of Standard Sample 140 were similarly examined before and after exposure. Both results were 0.0014 percent. On the basis of these results, the water content of these Standard Samples of benzoic acid is negligible for the purposes for which the acid is normally used. Since the Standard Sample acid is known to contain not more than about 0.02 mole percent of nonvolatile impurities, it may also be concluded that the pure substance, in the condition of moderately fine crystals, is not significantly hygroscopic at ordinary temperatures in an atmosphere having a relative humidity not higher than 90 percent.

\footnotetext{
4 George W. Morey, Benzoic acid as an acidimetric standard, J. Am. Chem. Soc. 34, 1027 (1912).

$\checkmark$ E. R. Weaver, The use of benzoic acid as a standard material, J. Am. Chem. Soc. 35, 1309 (1913).

6 W. Swiętosławski and S. Miernik, Bul. int. acad. polon. sci., Classe sci. math. nat. [A] 53-8 (1935).

7 W. Świętosławski, M. Wojciechowski, and S. Miernik, Bul. int. acad. polon. sci., Classe sci. math. nat. [A] 59-64 (1935).

${ }^{8}$ Ralph S. Jessup, Heat of combustion of benzoic acid, with special reference to the standardization of bomb calorimeters, J. Research NBS 29, 247 (1942) RP1499.

$39 \mathrm{f}$ is a Standard for acidimetry and for calorimetry, and 140 is a Standard for microchemistry. Both are currently issued by the National Bureau of Standards.

10 Since the determination was based on the pressure of the vapor, without identification of the volatile substance as water, this would be more strictly stated as 0.01 mole percent of volatile impurity, assumed to be water.
} 


\section{DETERMINATION OF BENZENE IN ACETANILIDE}

In the course of purifying a quantity of acetanilide to be used as a microchemical standard, W. H. Smith and W. W. Walton of this Bureau crystallized the material from a solution in benzene. To determine the amount of benzene retained by the crystals, the procedure herein described was applied to two samples, one of the rather coarse crystals after drying in air and the other of a portion of these crystals which had been crushed to smaller size. Acetanilide melts at $113.4^{\circ} \mathrm{C}$ and has a relatively low vapor pressure at that temperature. The benzene was accordingly very easily separated from it. On the basis of the pressure in the trap, $0.11_{2}$ percent by weight of benzene was found in the coarse crystals and $0.05_{1}$ in the finer ones. The vapor collected in the trap was then condensed in the capillary tube. The freezing point of the liquid in the tube was about $5^{\circ} \mathrm{C}$, which corresponds closely with that of benzene, and thus served to identify the volatile impurity.

\section{DETERMINATION OF A MIXTURE OF WATER AND ALCOHOL IN ACETANILIDE}

In the purification of another quantity of acetanilide, the material was recrystallized from its solution in a mixture containing about 20 percent (by weight) of water and 80 percent of ethanol. The crystals were crushed somewhat and dried under a reduced pressur 3 of several $\mathrm{mm}$ of mercury at $50^{\circ} \mathrm{C}$. The volatile constituents of a $20 \mathrm{-g}$ sample of these crystals were separated from the sample in the manner described and collected in a trap having a capacity of $121 \mathrm{ml}$. When the trap was warmed to about $25^{\circ} \mathrm{C}$, droplets of liquid on its walls indicated that a condition of saturation existed. Thus, the observed pressure was the vapor prassure of a liquid presumed to be a mixture of alcohol and water. Since this vapor pressure is relatively insensitive to changes in composition of the liquid, it could not be used to determine the proportion of alcohol and water. The volatile material was condensed in the capillary tube, which was sealed and separated from the train. By measurement of dimensions with a microscope, C. P. Saylor, of this Bureau, determined the volume of the liquid as $0.015 \mathrm{~cm}^{3}$ at $26^{\circ} \mathrm{C}$. He also measured the refractive index, and from this measurement and the relation between the refractive index and the percentage of alcohol by weight, he interpolated the percentage by weight of ethanol in the mixture, and from this value the density on the assumption that the liquid contained only ethanol and water. The percentage of ethanol in the mixture (by weight) was found to be about 60 percent. The weight of the liquid, determined directly by weighing the capillary tube before and after emptying it, was $0.0155 \mathrm{~g}$. This weight, together with the density calculated from the refractive index, yielded $0.017 \mathrm{ml}$ as the volume, which is in satisfactory agreement with the volume determined from the measurements made with the microscope.

\section{DETERMINATION OF WATER IN POTASSIUM DICHROMATE}

Examination by C. P. Saylor of potassium dichromate intended as a standard for oxidimetry showed that the crystals contained droplets of liquid, presumably trapped mother liquor. Determination 
of water in one sample of this salt, in accordance with the procedure herein described, yielded a value of $0.02_{7}$ percent by weight. A second sample was at first not fused but kept just below the melting point $\left(397.5^{\circ} \mathrm{C}\right)$, while the cell was being evacuated. Some decrepitation occurred when the salt was heated, but much more while it was cooling under reduced pressure. The crystals finally broke up into a powder. The water content thus determined was $0.01_{9}$ percent. The sample was then fused, whereupon the value determined for the water content was $0.02_{0}$ percent. The difference between this value and that for the first sample is believed to be considerably larger than the experimental error. It more probably represents nonuniformity in the samples. The complete elimination of water from potassium dichromate without melting the substance depends on a change of the crystalline form of the solid which occurs at a temperature of about $237^{\circ} \mathrm{C}$. A similar behavior is not to be expected in the case of all crystalline substances, and the complete elimination of water from them without melting cannot be depended on.

During repeated fusions of potassium dichromate, a slight but persistent evolution of gas bubbles occurred. This gas was believe to be oxygen. The low pressure existing during the evacuation makes this method of detecting decomposition extremely sensitive, and since the volume of the gas evolved was small, it is evident that the amount of decomposition was very slight. Oxygen could not be held in the trap, hence it could not cause errors in the determination of water.

\section{DISCUSSION}

From the illustrations which have been given, it will appear that the method is suitable for the determination of volatile impurities in a considerable variety of substances under the following conditions:

1. The impurity is insoluble in the solid form of the substance.

2. The impurity has at least a moderate vapor pressure, and the vapor does not depart significantly from the conditions of an ideal gas at room temperature, or at least at a temperature at which the trap and manometer can be uniformly maintained. Furthermore, the jmpurity also has a negligible vapor pressure at the temperature of liquid air.

3. The impurity is essentially a single substance of known molecular weight in the vapor state, and identifiable if its proportion by weight rather than its molal concentration is desired.

3a. If not a single substance, the components of the mixture must be known or identifiable unless it is sufficient to determine only their combined concentration.

The method is most readily adaptable to impurities in substances that are stable at the melting temperature, have a relatively low vapor pressure at that temperature, and an insignificant vapor pressure at room temperature.

Because of its relatively high sensitivity, the method is specially useful for such determinations as that of volatile impurities absorbed by crystals. For residues of solvents present as mother liquor entrapped within crystals, especially of inorganic salts, it has the advantage of a direct determination over the commonly used indirect method of observing the loss of weight on heating. Temperatures very much above the boiling point of water are often needed to set 
free the solvent by rupturing the crystalline structure within which the tiny droplets of mother liquor are confined. When this rupturing does occur, in the phenomenon of decrepitation, the resulting mechanical losses invalidate the indirect method of "drying".

Within the limitations already given, the method can be applied to the analysis of liquid substances as well as solid substances, provided they solidify in well-formed crystalline structures when suitably refrigarated. Examples of liquids which have the requisite large difference in vapor pressure from that of the impurity being determined are, of course, much less common than those of substances which are solid at ordinary temperatures.

An attractive feature of the method is that its precision can be adjusted within rather wide limits by the degree of refinement with which the measurements of volume, temperature, and pressure are made. For a high degree of accuracy, it will be necessary not only to use exact physical measurements but to use a refined technic in separating and collecting the impurity and in obviating or correcting for errors caused by retention of the vaporized impurity on the surfaces of the apparatus.

Thanks are expressed to C. L. Gordon for preparing the drawing appearing in this paper.

Washington, May 12, 1944. 